\title{
Opiate Pain Medication Consumption in Cigarette Smokers following Total Hip Arthroplasty
}

\author{
Jennifer I. Etcheson ${ }^{1}$ Chukwuweike U. Gwam ${ }^{1} \quad$ Nicole E. George $^{1} \quad$ Naval Walia $^{1} \quad$ Christophe Jerjian $^{1}$ \\ Ga-ram Han ${ }^{1}$ Sana Virani ${ }^{1}$ Seth J. Miller ${ }^{1}$ Ronald E. Delanois ${ }^{1}$ \\ ${ }^{1}$ Rubin Institute for Advanced Orthopedics, Center for Joint Preservation \\ and Replacement, Sinai Hospital of Baltimore, Baltimore, Maryland, \\ United States \\ Joints 2018;6:157-160. \\ Address for correspondence Ronald E. Delanois, MD, Rubin Institute \\ for Advanced Orthopedics, Center for Joint Preservation and \\ Replacement, Sinai Hospital of Baltimore, 2401 West Belvedere \\ Avenue, Baltimore, MD 21215, United States \\ (e-mail: rdelanoi@lifebridgehealth.org; delanois@me.com).
}

\begin{abstract}
Keywords

- total hip arthroplasty

- narcotics

- cigarette smoking

- opioids

- pain

Purpose The purpose of the present study was to assess perception of pain and pain management in smokers versus nonsmokers who received a total hip arthroplasty (THA). Methods Patients who underwent THA from 2010 to 2016 were propensity score matched 1:1 based on race, body mass index, age, and sex. This yielded 124 smokers and 124 nonsmokers. Pain intensity was quantified using area under the curve for visual analog scale pain scores. Opioid consumption was determined using a morphine milliequivalent $(\mathrm{mEq})$ conversion algorithm. An independent samples $t$-test and Chi-square analysis was conducted to assess continuous and categorical variables respectively.

Results Smokers experienced a nonsignificantly increased pain intensity (198.1 vs. 185.7; $p=0.063)$. Smokers demonstrated significantly higher opioid consumption in both immediate postoperative (65.9 vs. $59.3 \mathrm{mEq} ; p=0.045)$ and 90 days postoperative periods (619.9 vs. $458.9 \mathrm{mEq} ; p=0.029$ ).

Conclusion Our study demonstrated a nonsignificantly increased pain intensity, and (in both the immediate and 90 days postoperative periods) a significantly higher opioid consumption following THA in patients who smoke cigarettes. This may be due to a relatively small effect size, warranting the need for larger prospective studies. Nevertheless, arthroplasty surgeons should encourage preoperative smoking cessation and alternative nonopioid analgesics to smoking patients receiving THA.

Level of Evidence This is a level III, retrospective cohort study.
\end{abstract}

\section{Introduction}

Legislative pressures to improve patient satisfaction and value of care have placed the onus on arthroplasty surgeons to optimize patient health and recovery after total hip arthroplasty (THA). However, for many patients recovering from THA, postoperative pain management may be difficult to achieve. Patients with residual pain, slower recovery rates, and limited function may report poor pain management, a quality metric used to determine reimbursement for institutions and surgeons. ${ }^{1}$

received

April 18, 2018

accepted after revision

August 26, 2018

published online

October 18, 2018
DOI https://doi.org/

10.1055/s-0038-1673405. ISSN 2282-4324.
In an effort to improve patient perception of care, joint replacement, surgeons may choose pain management regimens including opioid analgesics, as they have shown great efficacy following orthopaedic procedures. ${ }^{2}$ However, increased opioid administration not only compounds the current dependency epidemic but also generates increased healthcare related costs and ineffective resource utilization. ${ }^{3,4}$ Furthermore, patient-specific factors, such as smoking status and excessive opioid consumption during the immediate postoperative period, may negatively affect outcomes. ${ }^{4}$

Copyright $\odot 2018$ Georg Thieme Verlag License terms KG Stuttgart · New York 
The complex association between tobacco smoking, perception of pain, and pain management has been investigated, with evidence supporting increased postoperative pain perception in patients who smoke. ${ }^{5,6}$ Nicotine contained within cigarettes modulate pain perception and the body's natural neuroendocrine opioid system, leading to increased pain and decreased analgesia from administered opioid medications. ${ }^{7}$ Furthermore, smokers display increased analgesic requirements postoperatively compared with nonsmokers following nonorthopaedic surgeries, correlating to an increased probability of developing opioid dependence., ${ }^{8,9}$ As such the connection among smoking, perception of pain, and opioids may be problematic for arthroplasty surgeons performing THA. Therefore, reducing healthcare spending and minimizing additional risks to patients, such as overuse of opioid analgesics for pain control, should be of paramount importance for healthcare professionals.

Identification of patient-specific factors, such as smoking status, could aid arthroplasty surgeons in modulating patients' course of recovery, which may lead to improve outcomes. Previous studies have demonstrated some association between smoking and opioid use; however, to our knowledge, no study exists assessing the association between smoking status and opioid consumption in THA patients.

The purpose of the present study was to assess the association between tobacco smoking, perception of pain, and pain management in THA patients. The hypothesis of the study was that there is a difference in terms of pain intensity, length of stay, patient satisfaction, and postoperative opioid consumption in smokers versus nonsmokers who received a THA.

\section{Methods}

\section{Patient Selection and Database}

Institutional review board approval was obtained for the retrospective review of all patients at a single institution who underwent primary THA and completed a Press Ganey survey from 2010 to 2016. The Press Ganey patient satisfaction survey contains 7 questions domains; however, our study focused on questionnaire responses to questions contained within the "pain management" component. Within the "pain management" domain there are three questions related to the patient's pain during their hospital stay, which includes need for medicine, pain well controlled, and mean pain rating. Patients were included in the study cohort if they had a history of cigarette smoking of $\geq 30$ packs/year. Patients were excluded if they had a history of smoking cessation at least 6 weeks prior to surgery, chronic pain syndrome, opioid abuse/ methadone use, diabetic neuropathy, and inflammatory arthropathy. Information such as patient demographics, American Society of Anesthesiology (ASA) scores, Visual Analog Scale (VAS), length of stay (LOS), and narcotic use during hospital admission are contained within the database.

A total of 614 patients were identified. A propensity score match analysis was conducted to limit the influence of confounders. Patients were matched by race, body mass index (BMI), age, and sex. This yielded a total of 124 smokers and 124 nonsmokers (-Table $\mathbf{1}$ ).
Table 1 Patient demographics of the two groups

\begin{tabular}{|c|c|c|c|}
\hline & Smokers & Nonsmokers & $p$-Value \\
\hline Sample size, $n$ & 124 & 124 & \\
\hline $\begin{array}{l}\text { Age }(y) \text {, mean } \\
\text { (range) }\end{array}$ & $63.2(28-90)$ & $65.3(24-91)$ & 0.106 \\
\hline Females, $n(\%)$ & $76(61.3)$ & $68(54.80)$ & \multirow[t]{2}{*}{0.367} \\
\hline Males, $n(\%)$ & $48(38.7)$ & $58(45.2)$ & \\
\hline $\begin{array}{l}\text { BMI, mean } \\
\text { (range) }\end{array}$ & $\begin{array}{l}28.8(19.4- \\
48.2)\end{array}$ & $\begin{array}{l}29.9(16.9- \\
63.1)\end{array}$ & 0.096 \\
\hline $\begin{array}{l}\text { Preop VAS score, } \\
\text { mean (range) }\end{array}$ & $3.2(0-10)$ & $3.3(0-10)$ & 0.969 \\
\hline \multicolumn{4}{|l|}{ ASA score, $n(\%)$} \\
\hline ASA I & $4(3.3)$ & $5(4.0)$ & \multirow[t]{4}{*}{0.241} \\
\hline ASA II & $84(70.0)$ & $75(60.5)$ & \\
\hline ASA III & $32(26.7)$ & $43(34.7)$ & \\
\hline ASA IV & $0(0.0)$ & $1(0.8)$ & \\
\hline \multicolumn{4}{|c|}{ Anesthesia type, $n(\%)$} \\
\hline Spinal & $36(29)$ & $45(36.3)$ & \multirow[t]{2}{*}{0.118} \\
\hline General & $88(71.0)$ & $79(63.7)$ & \\
\hline $\begin{array}{l}\text { Cigarettes per } \\
\text { year (packs), } \\
\text { range }\end{array}$ & $180-540$ & $\mathrm{~N} / \mathrm{A}$ & $\mathrm{N} / \mathrm{A}$ \\
\hline
\end{tabular}

Abbreviations: ASA, American Society of Anesthesiology; BMI, body mass index; N/A, not available; Preop, preoperative; VAS, Visual Analog Scale.

\section{Data Collection and Evaluation of Endpoints}

Pain was evaluated per protocol employed by our institution, using the VAS pain scores ranging from 0 (no pain) to 10 (worst possible pain). Preoperative pain score was obtained in the preoperative holding area 2 hours prior to surgery and was calculated as the algorithmic mean of tabulated VAS pain scores. Postoperative pain was evaluated by nursing staff every 8 hours. Postoperative pain intensity was quantified using the area under the curve (AUC) for the VAS scores for the first 48 hours of inpatient stay with the following equation $(\mathrm{Eq}):^{10}$

$$
\text { AUC }=\sum(\text { pain score } \times \Delta \text { time })
$$

LOSs were designated as the continuous LOS between the dates of admittance to the date of discharge from the orthopaedic service. Total opioid consumption in the first 48 hours postoperatively was calculated using a morphine milliequivalent ( $\mathrm{mEq}$ ) conversion model. ${ }^{11}$ Opioid consumption at 90 days postoperative was collected via patients' electronic medical record which was calculated as the algorithmic mean after converting to morphine $\mathrm{mEq}$. These endpoints were chosen due to previous reports suggesting their correlation with pain. ${ }^{12}$

\section{Statistical Analysis}

An independent samples $t$-test or Chi-square analyses were conducted to assess continuous and categorical variables, respectively. Analysis of covariance (ANCOVA) was utilized to assess the effects of smoking on postoperative pain intensity, 
Table 2 Comparison of pain intensity and LOS between groups

\begin{tabular}{|l|l|l|l|}
\hline & Smokers & Nonsmokers & $p$-Value \\
\hline $\begin{array}{l}\text { LOS (d), } \\
\text { median (range) }\end{array}$ & $\begin{array}{l}2.0 \\
(0-10)\end{array}$ & $\begin{array}{l}2.0 \\
(1-7)\end{array}$ & 0.467 \\
\hline $\begin{array}{l}\text { Pain intensity } \\
\text { (AUC), } \\
\text { mean, range }\end{array}$ & $\begin{array}{l}198.1 \\
(0-400)\end{array}$ & $\begin{array}{l}185.7 \\
(16-352)\end{array}$ & 0.063 \\
\hline
\end{tabular}

Abbreviations: AUC, area under the curve; LOS, length of stay.

while adjusting for preoperative pain score. Mixed design analysis of variance (ANOVA) was conducted to assess the difference in opioid consumption between the groups. A $p$-value of 0.05 was set as the threshold for statistical significance on two-tailed tests. All statistical analyses were conducted using SPSS V24 software (IBM, Armonk, New York, United States)

\section{Results}

Patients who smoke demonstrated a higher mean pain intensity score when compared with nonsmokers; however, this was not statistically different. There was no significant difference in LOS between the two study groups - Table 2 .

Smokers demonstrated a significantly higher opioid consumption both in the immediate postoperative period (first 48 hours) and at the 90 days postoperative time period (-Table 3).

Within the "pain management" domain of the Press Ganey patient satisfaction survey, there was no demonstrable correlation between responses provided by smokers and nonsmokers with regards to "need for medicine," "pain well controlled," and "mean pain rating" (-Table 4).

\section{Discussion}

Despite the effectiveness of THA and postprocedure pain management strategies, providing pain relief in the immediate postoperative period may be difficult to achieve for some patients. Increased emphasis has been placed on determining factors that influence pain perception, with the aim of improving patient outcomes and satisfaction, while decreasing the economic burden on healthcare.

While opioid pain medications provide effective analgesia for postoperative pain, they can induce a high rate of dependence. Identification of modifiable factors, such as preoperative tobacco smoking, may facilitate optimization of pain

Table 3 Comparison of opioid consumption between groups

\begin{tabular}{|l|l|l|l|}
\hline & Smokers & Nonsmokers & $p$-Value \\
\hline $\begin{array}{l}\text { 48 h (mEq), } \\
\text { mean (range) }\end{array}$ & $\begin{array}{l}65.9 \\
(0-337.7)\end{array}$ & $\begin{array}{l}59.3 \\
(0-327.0)\end{array}$ & 0.045 \\
\hline 90 d (mEq), & 619.9 & 458.9 & 0.029 \\
mean (range) & $(0-5985)$ & $(0-5340)$ & \\
\hline
\end{tabular}

Abbreviation: mEq, milliequivalent.
Table 4 Comparison of perception of pain management according to Press Ganey survey between groups

\begin{tabular}{|c|c|c|c|}
\hline & Smokers & Nonsmokers & $p$-Value \\
\hline \multicolumn{4}{|c|}{ Need medicine for pain, $n(\%)$} \\
\hline Yes & $112(90.3)$ & $114(91.9)$ & \multirow[t]{2}{*}{0.563} \\
\hline No & $12(9.7)$ & $10(8.6)$ & \\
\hline \multicolumn{4}{|c|}{ Pain well controlled, $n(\%)$} \\
\hline Never & $0(0.0)$ & $2(1.6)$ & \multirow[t]{4}{*}{0.214} \\
\hline Sometimes & $6(5.3)$ & $2(1.6)$ & \\
\hline Usually & 39 (31.6) & $36(29.0)$ & \\
\hline Always & $78(62.9)$ & $84(67.7)$ & \\
\hline $\begin{array}{l}\text { Pain rating, } \\
\text { mean (range) }\end{array}$ & $3.7(2-4)$ & $3.7(1-4)$ & 0.889 \\
\hline
\end{tabular}

perception, and therefore, reduce subsequent postoperative opioid consumption. Thus, we compared opioid consumption between smokers and nonsmokers following THA. Specifically, we compared pain intensity, LOS, patient satisfaction, and opioid consumption in the immediate and 90 days postoperative time points. Although not statistically different, our findings demonstrated an increased pain intensity among smokers undergoing THA, corroborating reports from previous investigations. ${ }^{13}$ Smokers receiving THA demonstrated significantly higher opioid consumption both in the immediate postoperative period and at 90 days post-operative.

Previous studies evaluating the correlation between tobacco smoking, acute postoperative pain, and opioid consumption demonstrate similar results to our findings. Turan and Kerstern prospectively evaluated pre-, intra-, and postoperative pain scores in 2,157 smokers from 12 institutions undergoing elective surgery with general anesthesia. ${ }^{14}$ The investigators collected verbal pain scores on a 10-point scale, using a score of 7 or greater to represent severe acute pain. Smoking was found to be an independent risk factor for immediate postoperative pain (odds ratio [OR], 1.74; 95\% CI [confidence interval], 1.26-2.41) and at 48 hours postdischarge from the hospital (OR, 2.25; 95\% CI, 1.64-3.09; $p>0.001$ ). Additionally, smoking was found to be an independent risk factor for immediate postoperative pain (OR, $1.74 ; 95 \% \mathrm{CI}, 1.26-2.41$ ) and at 48 hours postdischarge from the hospital (OR, 2.25; 95\% CI, 1.64-3.09; $p>0.001$ ). Similarly, in a prospective study conducted by Chiang et al, ${ }^{13}$ postoperative pain and postoperative opioid consumption was compared among 848 male patients undergoing surgery with varying smoking status (566 nonsmokers, 155 current smokers, and 127 past smokers). The authors reported that current smokers had significantly higher VAS on movement pain scores on postoperative day 1 compared with past smokers and nonsmokers $(p=0.004)$. Current smokers also had significantly higher VAS at rest pain scores on postoperative day 1 when compared with past smokers and nonsmokers $(p=0.006)$. Additionally, current smokers required more opioid analgesics, as measured by postoperative morphine consumption ( $\mathrm{mg}$ ) for pain control during the 
72-hour postoperative period when compared with nonsmokers and past smokers $(p<0.001)$.

Conversely, Flood et al conducted a prospective randomized control trial consisting of 20 women to determine the effects of a single $3 \mathrm{mg}$ dose of intranasal nicotine spray prior to awakening from uterine surgery on postoperative pain and the need for morphine analgesia. ${ }^{15}$ Women treated with a single dose of nicotine prior to emergence from anesthesia reported significantly lower VAS pain scores compared with the control cohort at 1-hour (7.6 vs. 5.3, $p<0.001$ ) and 24 hours postoperatively ( 1.5 vs. $4.9 ; p<0.01$ ). Furthermore, the researchers found that the nicotine nasal spray study group used significantly less morphine than the placebo group (12 mg vs. $6 \mathrm{mg} ; p<0.05$ ). The authors correlated these findings with an analgesic effect delivered by the administration of nicotine spray. However, Shi et al reported in their review on the pathophysiology of smoking and pain that while the use of nicotine in nicotine-naïve individuals may acutely provide analgesia, chronic nicotine use, as seen in smokers, modulates endogenous pain regulation systems leading to increased pain perception. ${ }^{7}$ Though acute administration of nicotine may provide pain relief in nicotine-naïve patients, chronic nicotine exposure predisposes smokers to increased pain.

Our study is not without limitations. Due to its retrospective design, we were unable to control for immeasurable confounders, such as varying pain thresholds among individual and time of surgery. Additionally, our patient satisfaction survey results may be influenced by self-selection bias, wherein patients who had a particularly pleasant or negative experience chose to return the questionnaire. However, this type of bias is inherent and acknowledged in all retrospective studies utilizing Press Ganey surveys. Also, this study evaluated patients from a single institution and may not be pertinent to all patient populations.

In conclusion, our report demonstrated that tobacco smokers showed a tendency to increased postoperative pain after THA when compared with a matched nonsmoking cohort. Furthermore, tobacco smokers used significantly more opioids in the immediate, and 90 days, postoperative period following THA. However, despite these differences in pain and opioid use, patient satisfaction did not vary between smokers and nonsmokers. Modifiable risk factors for increased pain intensity and opioid intake after THA, such as smoking status, is important for arthroplasty surgeons to recognize when planning postoperative and discharge pain management strategies. As such, administration of nonopioid analgesic adjuvants is encouraged, as they may not only optimize postoperative pain control, but may reduce the dependency epidemic. Moreover, arthroplasty surgeons are encouraged to discuss preoperative smoking cessation with patients prior to THA, as reduced pain and opioid consumption may be observed, in addition to improved wound healing and lower infection rate. However, larger prospective studies are needed to evaluate the effects of smoking cessation, and determine the duration of preoperative smoking cessation necessary to observe reduced pain intensity and decreased need for opioid analgesia.

\section{Conflict of Interest}

None declared.

\section{References}

1 McDonald LT, Corbiere NC, DeLisle JA, Clark AM, Kuxhaus L. Pain management after total joint arthroplasty. AORN J 2016;103(06): 605-616

2 Niitsuma M, Hirano T, Kunii T, et al. [A case of aneurysmal bone cyst arising from the right 3d rib]. Kyobu Geka 1986;39(06):488-490

3 Brummett CM, Waljee JF, Goesling J, et al. New persistent opioid use after minor and major surgical procedures in U.S. adults. JAMA Surg 2017;152(06):e170504

4 Soneji N, Clarke HA, Ko DT, Wijeysundera DN. Risks of developing persistent opioid use after major surgery. JAMA Surg 2016;151 (11):1083-1084

5 Topaloğlu N, Tekin M, Yıldırım S, Küçük A, Gönüllü B, Hancı V. Passive smoking increases pain perception in children undergoing venous catheterization. Acta Paediatr 2013;102(11):e493-e496

6 Hanci V, Kiraz HA, Omür D, et al. [Effects of smoking on venous cannulation pain: a randomized prospective trial]. Rev Bras Anestesiol 2015;65(01):47-50

7 Shi Y, Weingarten TN, Mantilla CB, Hooten WM, Warner DO. Smoking and pain: pathophysiology and clinical implications. Anesthesiology 2010;113(04):977-992

8 Billert H, Gaca M, Adamski D. [Smoking cigarettes and painimplications for the postoperative period]. Przegl Lek 2007;64 (10):882-885

9 Creekmore FM, Lugo RA, Weiland KJ. Postoperative opiate analgesia requirements of smokers and nonsmokers. Ann Pharmacother 2004;38(06):949-953

10 McGraw-Tatum MA, Groover MT, George NE, Urse JS, Heh V. A prospective, randomized trial comparing liposomal bupivacaine vs fascia iliaca compartment block for postoperative pain control in total hip arthroplasty. J Arthroplasty 2017;32(07):2181-2185

11 Gilson AM, Maurer MA, Ryan KM, Rathouz PJ, Cleary JF. Using a morphine equivalence metric to quantify opioid consumption: examining the capacity to provide effective treatment of debilitating pain at the global, regional, and country levels. J Pain Symptom Manage 2013;45(04):681-700

12 Hill DL. Experience with microsurgical reversal of female sterilization. Minn Med 1985;68(11):846-848

13 Chiang H-L, Chia Y-Y, Lin H-S, Chen C-H. The implications of tobacco smoking on acute postoperative pain: a prospective observational study. Pain Res Manag 2016;2016:9432493

14 Turan, Kersten. Smokers experience more postoperative pain than nonsmokers. American Society of Anesthesiologists, 2010. Available at: http://nx.mednemo.it/?p=2894

15 Flood P, Daniel D. Intranasal nicotine for postoperative pain treatment. Anesthesiology 2004;101(06):1417-1421 